\title{
Diagnostic Efficacy
}

National Cancer Institute

\section{Source}

National Cancer Institute. Diagnostic Efficacy. NCI Thesaurus. Code C70923.

The ability of a detection reagent or method to differentiate between positive and negative cases. 